\title{
Determinant and outcome of early diagnosis of HIV infection among HIV-exposed infants in southwest Ethiopia
}

\author{
Gebremedhin Derebe ${ }^{1}$, Sibhatu Biadgilign ${ }^{1,2^{*}}$, Marina Trivelli ${ }^{3}$, Gemechis Hundessa ${ }^{1}$, Zinash D Robi ${ }^{1}$,
} Mikael Gebre-Mariam ${ }^{1}$ and Misrak Makonnen ${ }^{4}$

\begin{abstract}
Background: Preventing mother-to-child transmission (PMTCT) of human immunodeficiency virus infection (HIV) has been a fundamental advancement in the acquired immunodeficiency syndrome (AIDS) response for the past decade. Several countries have made great strides in the efforts to prevent HIV through mother-to-child transmission. The objective of this study is to assess the determinant and outcome of early diagnosis of HIV infection among HIV-exposed infants in southwest Ethiopia.

Methods: An institutional based retrospective cohort study was conducted in a hospital. Medical records of HIV-exposed infants and their mothers enrolled into the program were reviewed. Data entry and analysis was carried out using SPSS version 20 for Windows.
\end{abstract}

Results: A total of 426 HIV exposed infant-mother pairs where both mother and infants received a minimum ARV intervention for PMTCT were included in the study. Two hundred fifty-four (59.6\%) of mothers had attended antenatal care (ANC). Of all participants, 234(54.9\%) mothers did not receive any PMTCT prophylaxis during ANC, while only 104(24.4) received antiretroviral (ART) as PMTCT prophylaxis and 163(38.3\%) claimed that did not observe any infant PMTCT interventions while 135(31.7\%) of the infants received single-dose NVP + AZT. About 385(90.4\%) infants were not infected at their final infection status. Those mothers who did not attended ANC follow-up, infants on mixed and complementary feeding and infants weaned off and mothers who were in WHO clinical stage III and IV were more likely to have HIV sero positive infant.

Conclusion: This study showed that 385(90.4\%) of the infants were not infected at their final infection status. Therefore, encouraging pregnant women to visit health facilities during their course of pregnancy, focusing on exclusive breast feeding counseling and promotion, and early initiation of antiretroviral treatment to HIV infected pregnant women are recommend.

Keyword: Outcome, EID, HIV infection, HIV-exposed infants, Ethiopia

\section{Background}

In 2001, the United Nations General Assembly Special Session (UNGASS) placed a clear emphasis on the effect of HIV/AIDS on maternal and child health. The final declaration of commitment1from the assembly stated that the proportion of infants infected with HIV should

\footnotetext{
* Correspondence: sibhatu2005@yahoo.com

${ }^{1}$ Ethiopian Catholic Church, Health and HIV/AIDS Department, Addis Ababa, Ethiopia

${ }^{2}$ Independent Public Health Consultant, Addis Ababa, Ethiopia

Full list of author information is available at the end of the article
}

be reduced by $20 \%$ by 2005 , and by $50 \%$ by 2010 . This goal was to be reached by ensuring that $80 \%$ of pregnant women who receive antenatal care have access to HIV-1 prevention services [1]. More than $90 \%$ of new paediatric HIV cases are acquired through mother-to-childtransmission [2]. Several studies have shown that child mortality increases substantially in children who are infected with HIV via their mothers [3-5].

Mother-to-child transmission (MTCT) of HIV accounts for $14 \%$ of all new HIV infections worldwide, and may occur during pregnancy, labor and delivery or

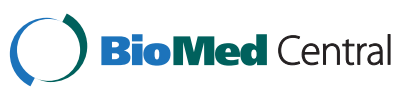


breastfeeding. In the absence of prevention, rates of MTCT are estimated to be $25-35$ percent [6,7]. Therefore, HIV counseling and testing for pregnant women is therefore considered as a key factor for the success of PMTCT $[8,9]$. Detection of maternal infection early in pregnancy through voluntary counseling and HIV testing (VCT) is critical for PMTCT [10]. PMTCT of HIV has been a fundamental advance in the AIDS response for the past decade. Infection rates among children born to mothers living with HIV, 370000 children were infected with HIV in 2009. Seven other countries in sub-Saharan Africa have coverage levels of $50 \%$ to $80 \%$. Sub-Saharan Africa as a whole achieved 54\% [40\%-84\%] coverage [11].

Ethiopia has adopted the WHO/UNICEF/UNAIDS 4-pronged PMTCT strategy as a key entry point to HIV care for women, men and families [12]. According to Ethiopia Demographic and Health Survey (EDHS) 2011, the national adult HIV prevalence was $1.5 \%$ with women disproportionately infected (1.9\% compared to $1.0 \%$ in men) [13]. The national estimate for HIV positive pregnant women needing PMTCT was 38,404 for the year 2012 [14]. In most resource-limited countries, PCR-based assays are not available for the early diagnosis of pediatric HIV. The high mortality rate of pediatric HIV in resourcelimited countries is partly due to lack of early diagnosis and low coverage of pediatric highly active antiretroviral therapy (HAART) treatment. There is an urgent need to integrate low-cost and accessible viral nucleic acid based assays $[15,16]$. So the objective of this study is to assess the determinant and outcome of early diagnosis of HIV infection among HIV-exposed infants in southwest Ethiopia.

\section{Methods}

\section{Study settings and context}

Health institution-based retrospective cohort study was conducted at St. Luke Hospital from December 2009 to March 2010 to evaluate the determinant and outcome of EID (Early Infant Diagnosis) of HIV infection. The study was conducted in Woliso town, Southwest Shewa administrative zone; one of the eighteen zones in Oromia Regional State. Woliso is the capital city of the zone which is located $114 \mathrm{Km}$, South-west of Addis Ababa. The administrative zone has 11 rural districts. The hospital was established on January 1, 2001 [17].

\section{Study design and participants}

Participants for this study were mother-child pairs registered from the start of the program of antiretroviral treatment service including PMTCT. Medical records of HIV-exposed infants and their mothers enrolled into the program were reviewed for study inclusion. To be eligible for inclusion, both mother and child had to be enrolled in the PMTCT program and their data available during data collection period. All HIV-positive women should be routinely assessed for ART eligibility and initiated on HAART if eligible, at the point of care or at HIV care/ART clinic ensuring the follow-up of comprehensive care and treatment for HIV exposed infants ranging from follow-up visits, counsel about infant feeding practices and support mother's choice, provision of cotrimoxazole prophylaxis starting at 4-6 weeks old and DNA PCR testing at 6 weeks or as early as possible thereafter if not possible at 6 weeks [12].

\section{Data collection procedures and measurement}

Information on demographic characteristics, HIV testing and counseling(HCT), and uptake of different components of the PMTCT package were obtained from HIV exposed infant follow-up cards, HIV care/ART follow up cards and intake forms, HCT, PMTCT registers and antenatal patient cards, abstracted demographic, clinical, and pregnancy outcome data from delivery and newborn records, using standard abstraction forms. Data extraction was made by the team of the investigators. Before data extraction process, all the investigators were all orientated on how to complete the structured data collection sheet. According to the revised guidelines of PMTCT, it is recommended that all women coming for ANC, labour and delivery and post partum follow-up, if not tested during current pregnancy should be routinely informed about the benefits of HIV testing for mother and baby in a group or individual basis and tested or offered testing. Care of newborn to HIV-positive Mothers states that follow up should be schedule at 6 hours, 6 days, 6 weeks, 10 weeks, 14 weeks, then monthly until 6 months, and thereafter every 3 months until 18 months if infant is asymptomatic and wherever possible carry out DNA PCR testing at 6 weeks or as early as possible thereafter if not possible at 6 weeks. If the child is less than 18 months of age, HIV virological test (DNA PCR using DBS) will be done to say DNA PCR test using DBS is done at 6 weeks to identify infected infants, not to exclude infection [12]. The electronic medical record of the mother and the corresponding infants were cross-checked for the availability of their data and were linked with infant records in order to confirm maternal prophylaxis data during the appointment period. To ensure quality of the data, the following measures were taken: pre testing of the questionnaire, checking of completed questionnaires before data entry, supervision of data entry and errors and consistency checking procedures for the data were controlled during analysis. The dependent (outcome) variable was the infant HIV status at the end of the program (18 months).

\section{Statistical analysis}

The data extraction from the medical records was checked for completeness and consistency. Data entry and analysis was carried out using SPSS version 20 for 
Windows (SPSS, Chicago, IL, USA). Descriptive statistical methods, bivariate analysis and multivariable logistic regression analysis were used. Odds ratio with its corresponding 95\% confidence interval was used as the measure of the degrees association with infant HIV positivity. P-value less than 0.05 were considered significant.

\section{Ethical considerations}

Ethical clearance was obtained from the local Research and Publication Committee of the St. Luke Hospital (Ref.157/2012, issued 11 of June 2012). Since the study utilizes routinely collected, aggregated program data at the hospital, confidentiality of patient information was ensured as the names or identification number of study participants was not included in the data collection format.

\section{Results}

A total of 426 mother-infant pairs where both mother and infants received a minimum ARV intervention for PMTCT. From this, 221(51.9\%) of the infants were male gender. The detailed description of the demographic and clinical characteristics is described in Table 1.

\section{ANC attendance and referral to care and treatment}

Two hundred fifty-four (59.6\%) of the mother had attended antenatal care (ANC). About 46(10.8\%) of the mothers had $<200$ and $180(42.3 \%)$ unknown CD4 count during their ANC. Similarly, 171(40.1\%) and 180(42.3\%) were in WHO stage I and unknown maternal clinical stage during ANC respectively. From the participants, 234(54.9\%) of them did not receive any PMTCT prophylaxis by the mother during ANC while only 104 (24.4) receive ART as a PMTCT prophylaxis. About $250(58.7 \%)$ of mothers gave delivery in health facilities and while 137(32.2\%) delivered at home. Majority of the participants $362(85.0 \%)$ delivered through spontaneous vaginal delivery. About 247(58.0\%) of the mothers took intra partum ARV prophylaxis. One hundred four (24.4\%) and 77(18.1\%) of the mothers received HAART and combined ARV prophylaxis during labor respectively. Approximately 163(38.3\%) of the participants claimed they did not attended any infant PMTCT interventions while 135(31.7\%) of the infants received single-dose NVP + AZT. Interestingly, 343(80.5\%) of the children were appropriate for their development for their age and 315(73.9\%) of them had a normal growth pattern.

\section{Breastfeeding pattern}

About 342(80.3\%) of the mothers mentioned that Exclusive breastfeeding (EBF) is the chosen infant feeding option. Regarding the sero status of the father, 188(44.1\%) and $182(42.7 \%)$ of the cases the result turn to be positive and not tasted respectively. About 318(74.6\%) the cases, the result of DNA PCR result of the infant were negative. Concerning infant feeding practice, 193(45.3\%) of the mother mentioned that their infant is weaned off where as $99(23.2 \%)$ as infant on exclusive breast feeding. About 115(27.0\%) and 204(47.9\%) of the infants started their complementary feeding at the age after 6 months and unknown duration. Significant proportion $88(20.7 \%)$ of infants were also started at about 4-6 months. From those who already started, 134(31.5\%) them gave breast feeding for about 6-12 months duration. Nearly half of 210(49.3) of the mother were at WHO stage I during breast feeding. Similarly, 78(18.3\%) of them were on WHO stage II. Likewise, 240(56.3) and 102(23.9) of the mothers were on Pre-ART and ART respectively during breast feeding. From those who started the ARV treatment, 92(21.6\%) was good adherence status. About 196 (46.0\%) and 90(21.1\%) of the participants have $>350$ and unknown $\mathrm{CD} 4$ count during breastfeeding.

\section{Outcome of the cohort}

About 385(90.4\%) of the infants were not infected at their final infection status. The final outcome of the children under this cohort were 171 (40.1\%) discharged and 168 $(39.4 \%)$ lost. Similarly, the age at which the children were discharged from the program at $86(20.2 \%)$ and $73(17.1 \%)$ of the cases were $<1$ year and $12-18$ month.

\section{Factor associated with prevalence of HIV infection among HIV-exposed infant}

Those mother whose didn't have ANC follow up were five times more likely to have HIV sero positivity infant than those mother who had ANC visits[ OR $=5.28,95 \%$ $\mathrm{CI}=2.24,12.45]$. Those mother whose Infant is on mixed feeding were six times $[\mathrm{OR}=6.63,95 \% \mathrm{CI}=1.23,35.56]$, Infant on complementary feeding ten times $[\mathrm{OR}=10.04$, $95 \% \mathrm{CI}=2.57,39.22]$ and Infant weaned off were ten times more likely to have HIV sero positivity infant $[\mathrm{OR}=10.43$, $95 \% \mathrm{CI}=2.10,51.86]$ compared with Infant on exclusively breastfeeding. Mothers who were in WHO clinical stage III were six times $[\mathrm{OR}=6.12,95 \% \mathrm{CI}=1.87,20.07]$ and WHO clinical stage IV were ten times $[\mathrm{OR}=10.23$, 95\% $\mathrm{CI}=1.34,78.0]$ more likely to have HIV sero positivity infant than those mothers who are WHO clinical stage I [Table 2].

\section{Discussion}

The study demonstrated that $163(38.3 \%)$ of the participants claimed that didn't observe any infant PMTCT interventions while $135(31.7 \%)$ of the infants received single-dose NVP + AZT. About 318(74.6\%) the cases, the result of DNA PCR result of the infant were negative and 193(45.3\%) of the mother mentioned that their infant is weaned off where as $99(23.2 \%)$ as infant on exclusive breast feeding. Those mothers who did not attended 
Table 1 Demographic and clinical characteristics of the study participants, southwest Ethiopia, 2010

\begin{tabular}{ll}
\hline Characteristics & Frequency(percentage) \\
\hline Gender & \\
Male & $221(51.9)$ \\
Female & $205(48.1)$
\end{tabular}

Mothers attended ANC

Yes

No

Not available

254(59.6)

114(26.8)

$58(13.6)$

Maternal CD4 count during ANC

$$
<200
$$

$>350$

Not done

Not available

Maternal clinical stage during ANC

WHO stage I
WHO stage II
WHO stage III
WHO stage IV
Not available

Type of PMTCT prophylaxis received by the mother during ANC

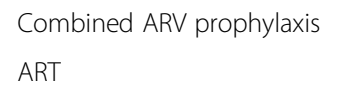

Not documented

None

46(10.8)

$74(17.4)$

124(29.1)

2(0.5)

180(42.3)

171(40.1)

46(10.8)

$27(6.3)$

2(0.5)

180(42.3)

Mother's place of delivery

Home
Health facility
Not available
Mode of delivery
Caesarian section
Spontaneous vaginal delivery
Not documented

Mothers took intra partum ARV prophylaxis

Yes

Not documented

Types of ARV received by mother during labor

Single-dose NVP
Combined ARV prophylaxis
HAART
None
Not documented

$$
76(17.8)
$$$$
\text { 104(24.4) }
$$$$
12(2.8)
$$$$
\text { 234(54.9) }
$$

104(24.4)

145(34.0)

32(7.5)
Table 1 Demographic and clinical characteristics of the study participants, southwest Ethiopia, 2010 (Continued)

Type of infant PMTCT interventions

$$
\begin{aligned}
& \text { Single-dose NVP } \\
& \text { Single-dose NVP + AZT } \\
& \text { Not documented } \\
& \text { None }
\end{aligned}
$$

135(31.7)

$39(9.2)$

163(38.3)

Infant feeding option chosen

Exclusive replacement feeding(ERF)

23(5.4)

Exclusive breastfeeding (EBF)

342(80.3)

Not available

61(14.3)

Father's HIV status

$\begin{array}{ll}\text { Positive } & 188(44.1) \\ \text { Negative } & 41(9.6) \\ \text { Not tested } & 182(42.7) \\ \text { Separated } & 15(3.5) \\ \text { DNA PCR result of the infant } & \end{array}$

$\begin{array}{ll}\text { Not done } & 65(15.3) \\ \text { Negative } & 318(74.6) \\ \text { Positive } & 31(7.3) \\ \text { indeterminate pending } & 12(2.8)\end{array}$

Infant feeding practice

Infant on exclusive breast feeding 99(23.2)

Infant is on exclusive replacement feeding 24(5.6)

Infant is on mixed feeding 22(5.2)

Infant is on complementary feeding 48(11.3)

Infant is weaned off 193(45.3)

Not documented 40(9.4)

Age at which complementary feeding is started

Before 4 months
4-6 months
After 6 months
Not documented
Duration of breast feeding

88(20.7)

115(27.0)

204(47.9)

$<6$ months

$9(2.1)$

6-12 months

134(31.5)

12-18 months

$41(9.6)$

$>18$ months

$11(2.6)$

Not documented

231(54.2)

Maternal clinical stage during breast feeding

$\begin{array}{ll}\text { WHO stage I } & 210(49.3) \\ \text { WHO stage II } & 78(18.3) \\ \text { WHO stage III } & 32(7.5) \\ \text { WHO stage IV } & 6(1.4) \\ \text { Not documented } & 100(23.5)\end{array}$


Table 1 Demographic and clinical characteristics of the study participants, southwest Ethiopia, 2010 (Continued)

Maternal status during breast feeding

On Pre ART

240(56.3)

On ART

102(23.9)

Not enrolled/Unknown

61(14.3)

Not applicable

23(5.4)

Maternal adherence to ART

$\begin{array}{ll}\text { Good } & 92(21.6) \\ \text { Fair } & 2(0.5) \\ \text { Poor } & 3(0.7)\end{array}$

Mother on Pre ART

238(55.9)

Not applicable

Maternal CD4 count during breastfeeding

$<200$

200-350

$>350$

Not documented

Developmental pattern of the child

Appropriate

Delayed

Not documented

Growth pattern of the child

Normal

Abnormal

Not documented

Final infection status of the infant

Infected

Not infected

Infant outcomes

Discharged

Lost

Dead

On HAART

Still on follow up

Transfer out

Age at discharge from the programme

$<1$ year

86(20.2)

12-18 months

$73(17.1)$

18 months

7(1.6)

$>18$ months

$5(1.2)$

Not documented

255(59.9)
ANC follow-up, infants on mixed and complementary feeding and infants weaned off and mothers who were in WHO clinical stage III and IV were more likely to have HIV sero positive infant.

In most of the cases, without the intervention of any PMTCT program, 30-45\% of infants born to HIV-positive mothers in developing countries become infected during pregnancy, delivery and breastfeeding [18]. In this study, two hundred fifty-four (59.6\%) of the mother had attended antenatal care (ANC). This reflects the low usage of ANC service utilization hence only 234(54.9\%) of them didn't receive any PMTCT prophylaxis by the mother and those mother whose didn't have ANC follow up were five times more likely to have HIV sero positivity infant than those mother who had ANC visits. Similar studies have shown that in Nigeria, seventy-three mother-baby pairs were not opportune to get ARV prophylaxis and 39 babies were PCR-positive (53.4\%) [19] and patient attrition along with the lower ANC attendance rate of $58 \%$ observed in Nigeria, is likely to contribute to the suboptimal uptake of ARV prophylaxis for PMTCT [20]. In contrary to this, PMTCT ANC services are feasible in resource limited settings whereby $80 \%$ of ANC attendees accepted the HIV test and a majority of the HIV positive women commenced ARV prophylaxis [21,22]. So encouraging pregnant women to have ANC is a crucial step to eliminate the virtual HIV transmission to the newborn babies and achieving the HIV free generation from the globe.

In order to avoid the increased incidence of diarrhea, pneumonia, and death observed with replacement feeding, WHO recommends breastfeeding duration for 2 years or longer [23,24]. In this study, 99(23.2\%) infant were on exclusive breast feeding practice. Breastfeeding in many settings may continue through the first $2-3$ years of life, suggesting an important role for repeat testing to confirm HIV-negative diagnoses [25]. The probability of HIV positive infants were more pronounced in those who have started on complementary feeding and infant weaned off. In case, if infants are found to be uninfected, decisions to avoid early mixed feeding and to shorten the duration of breastfeeding to 12 months will suffice for prevention of HIV infections [26,27]. Similarly, the rate of mixed feeding is high and so the risk of MTCT is increased [28] and overall MTCT rate of $18.5 \%$ among breastfed babies, and $68.0 \%$ among mixed fed babies were found in Southeastern Nigeria [19]. Other study in south Africa also demonstrated that exclusive breastfeeding carried a lower risk of HIV transmission than mixed feeding and a similar risk to no breastfeeding in Durban, South Africa [29]. We found that 88(20.7\%) of infants were also started complementary food about 4-6 months. In another study, in Rwandan national PMTCT programme, the majority of women in their study reported a HIV-free survival rate at nine to 24 months is 


\begin{tabular}{|c|c|c|c|c|c|c|}
\hline \multirow[t]{2}{*}{ Variables } & \multicolumn{2}{|l|}{ Infection status } & \multirow{2}{*}{$\begin{array}{l}\text { Crude OR } \\
(95 \% \mathrm{Cl})\end{array}$} & \multirow[t]{2}{*}{ P-value } & \multirow{2}{*}{$\begin{array}{l}\text { Adjusted OR } \\
(95 \% \mathrm{Cl})\end{array}$} & \multirow[t]{2}{*}{ P-value } \\
\hline & Positive n (\%) & Negative n (\%) & & & & \\
\hline Mother had ANC visits & & & & 0.001 & & 0.001 \\
\hline Yes & $11(4.3)$ & 243(95.7) & 1 & & 1 & \\
\hline No & $24(21.1)$ & $90(78.9)$ & $5.9(2.77,12.5)$ & & $5.284(2.243,12.447)$ & \\
\hline Unknown & $6(10.3)$ & $52(89.7)$ & $2.55(0.90,7.20)$ & & $2.373(0.576,9.781)$ & \\
\hline Infant feeding practice & & & & 0.001 & & 0.011 \\
\hline Infant on exclusively breastfeeding & $3(3)$ & $96(97)$ & 1 & & 1 & \\
\hline Infant on replacement breastfeeding & $2(8.3)$ & 22(91.7) & $2.91(0.46,18.47)$ & & $3.452(0.458,26.020)$ & \\
\hline Infant on mixed breastfeeding & $4(18.2)$ & 18(81.8) & $7.11(1.47,34.5)$ & & $6.626(1.234,35.561$ & \\
\hline Infant on complementary breastfeeding & $14(29.2)$ & $34(70.8)$ & $13.18(3.57,48.68)$ & & $10.039(2.569,39.223)$ & \\
\hline Infant weaned off & $15(7.8)$ & 178(92.2) & $2.7(0.76,9.55)$ & & $10.427(2.097,51.856)$ & \\
\hline Unknown & $3(7.5)$ & $37(92.5)$ & $2.59(0.50,13.44)$ & & $1.995(0.365,10.898)$ & \\
\hline Maternal clinical stage during breast feeding & & & & 0.004 & & 0.014 \\
\hline Stage I & $11(5.2)$ & 199(94.8) & 1 & & 1 & \\
\hline Stage II & $10(12.8)$ & $68(87.2)$ & $2.66(1.08,6.54)$ & & $1.633(0.587,4.546)$ & \\
\hline Stage III & $8(25)$ & $24(75)$ & $6.03(2.21,16.46)$ & & $6.123(1.868,20.072)$ & \\
\hline Stage IV & $2(33.3)$ & $4(66.7)$ & $9.04(1.49,54.87)$ & & $10.226(1.341,77.998)$ & \\
\hline Unknown & 10(10) & $90(90)$ & $2.01(0.82,4.90)$ & & $1.625(0.447,5.902)$ & \\
\hline
\end{tabular}

similar to the 12-to 18-month HIV-free survival rate of 95\% [30].

In Nigerian study, forty-seven babies (15.5\%) were mixed-fed and thirty-two (68.0\%) of them turned out PCR-positive. Two hundred and twenty-eight babies (75.0\%) were never breastfed, out of which 11 (4.8\%) were PCR-positive. Only 35.5\% (27 out of 76) of babies were exclusively breastfed. Five (18.5\%) of exclusively breastfed babies were found to be PCR-positive [19]. In another study, it is clearly demonstrated that in children $>6$ months the positivity rate was significantly higher in breast fed $42.8 \%(3 / 7)$ as compared to non breast fed 5\% (2/40) children [31]. The more likely explanation for this is that mixed breast feeding and early initiation of complementary feeding practice exacerbate the increasing vulnerability of HIV positivity to their infants. Our finding is also supported by most literatures in the area and the risks of mother-to-child transmission by breastfeeding duration which depends on studies with short breastfeeding durations, and difficult to distinguish exclusive from mixed breastfeeding [32].

Interestingly, in our study, we found that as the severity of maternal clinical stage is found to be associated with infants HIV positivity. Studies showed that children whose mothers had evidence of advanced HIV disease were at substantially increased risk of death [33] and 18month HIV transmission [34] and coincide across morbidity, mortality, and growth of HIV-exposed, HIV uninfected children [35] and rapidity of disease progression [36,37], and transmit HIV [38,39]. This shows the fact that women might be recently infected or had more advanced disease and therefore transmitted higher levels of HIV to their infants and as well the virus strains in these women were more virulent and convey less effective passive immunity to their infants [40].

The finding of this study should be interpreted in light of some limitations. The recall bias on remembering of the breast feeding pattern, the retrospective nature of data collection might have some measurement error. We also anticipated for selection bias as the participants were actually found in the health institution whereby receiving some interventions. Despite this, the participants were followed over long period of time and the paucity of literature in the country particularly evaluating the effectiveness of PMTCT services, it shade a light on the quality and efficacy of the PMTCT.

\section{Conclusion}

In conclusion, about $385(90.4 \%)$ of the infants were not infected at their final infection status. So encouraging pregnant women to visit health facilities during their course of pregnancy would contribute to increase the uptake of PMTCT interventional program, focusing on exclusive breast feeding counseling and promotion, and early initiation of antiretroviral treatment to HIV infected pregnant women contribute to the elimination of transmission to HIV to the new born babies and uninfected partners beyond the core asset of PMTCT services. 


\section{Competing interest}

There is no conflict of interest as a result of publication of this article.

\section{Authors' contribution}

GD conceived and designed the study, data extraction, performed analysis and interpretation of data and drafted the manuscript. SB, GH assisted the study design, data interpretation, drafted and critically reviewed the manuscript. MT, MG, ZD, MM assisted in interpretation of data, manuscript preparation and critically reviewed the manuscript. All authors read and approved the final manuscript.

\section{Acknowledgments}

We acknowledge the hospital staff for their kind cooperation and for their unreserved support during data collection of this project. Dr. Peter Memiah acknowledged for editing the manuscript.

\section{Author details}

${ }^{1}$ Ethiopian Catholic Church, Health and HIV/AIDS Department, Addis Ababa, Ethiopia. ${ }^{2}$ Independent Public Health Consultant, Addis Ababa, Ethiopia. ${ }^{3}$ St. Luke Catholic Hospital and College of Nursing and Midwifey, Wolliso,

Ethiopia. ${ }^{4}$ IntraHealth International, Addis Ababa, Ethiopia.

Received: 16 May 2014 Accepted: 19 May 2014

Published: 22 May 2014

\section{References}

1. Assembly UUNG: Final declaration of commitment on HIV/AIDS (A/S-26/L.2). New York: 2001. http://www.unaids.org/UNGASS/index.html. (Accessed January 18, 2012).

2. The United Nations Children's Fund (UNICEF): State of the world's children. Excluded and Invisible. New York: UNICEF; 2006

3. Spira R, Lepage P, Msellati P, Van De Perre P, Leroy V, Simonon A, Karita E, Dabis F: Natural history of human immunodeficiency virus type 1 infection in children: a five year prospective study in Rwanda. Pediatrics 1999, 104(10):e56.

4. Bobat R, Moodley $\mathrm{CH}$, Coutsoudis A: Mortality in a cohort of children born to HIV-1 infected women from Durban, South Africa. SAMJ 1999, 89:46-48.

5. Ota MO, O'Donovan D, Alabi AS, Milligan P, Yamuah LK, N'Gom PT, Harding E, Ariyoshi K, Wilkins A, Whittle HC: Maternal HIV-1 and HIV-2 infection and child survival in The Gambia. AIDS 2000, 14(4):435-439.

6. UNAIDS: Global report: UNAIDS report on the global AIDS epidemic 2010 Geneva: UNAIDS; 2010

7. Expanded Inter-Agency Task Team (IATT) on Prevention of HIV Infection in Pregnant Women, Mothers and their Children: A Report Card on PMTCT of HIV and Pediatric HIV Care and Treatment in Low and Middle Income Countries; scaling up progress from 2004-2005. New York: 2007.

8. Fabiani M, Cawthorne A, Nattabi B, Ayella EO, Ogwang M, Declich S: Investigating factors associated with uptake of HIV voluntary counseling and testing among pregnant women living in North Uganda. AIDS Care 2007, 19:733-739.

9. Rakgoasi SD: HIV counseling and testing of pregnant women attending Antenatal clinic in Botswana 2001. J Health Popul Nutr 2005, 23(1):58-65.

10. Bassett M: Ensuring a public health impact of programs to reduce HIV transmission from mothers to infants: the place of voluntary counseling and testing. Am J Public Health 2002, 92:347-351.

11. Joint United Nations Programme on HIV/AIDS (UNAIDS): Global report: UNAIDS report on the global AIDS epidemic 2010 WHO/UNIAIDS. "UNAIDS/ 10.11E | JC1958E"; 2010.

12. FMOH: Guidelines for Prevention of Mother-to-Child Transmission of HIV in Ethiopia. Addis Ababa: Ministry of Health; 2007

13. CSA: Central Statistical Agency [Ethiopia] and ICF International. Ethiopia Demographic and Health Survey 2011. Addis Ababa, Ethiopia and Calverton Maryland, USA: Central Statistical Agency and ICF International; 2012.

14. FMOH/FHAPCO: HIV/AIDS Estimates and Projections in Ethiopia, 2011-2016; 2012. Available at http://www.etharc.org/resources/healthstat/hivaidsestimates.

15. Creek T, Tanuri A, Smith M, Seipone K, Smit M, Legwaila K, Motswere C, Maruping M, Nkoane T, Ntumy R, Bile E, Mine M, Lu L, Tebele G, Mazhani L, Davis MK, Roels TH, Kilmarx PH, Shaffer N: Early diagnosis of human immunodeficiency virus in infants using polymerase chain reaction on dried blood spots in Botswana's national program for prevention of mother-to-child transmission. Pediatr Infect Dis J 2008, 27(1):22-26.

16. Zhang $Q$, Wang L, Jiang $Y$, Fang L, Pan P, Gong S, Yao J, Tang YW, Vermund $\mathrm{SH}$, Jia $\mathrm{Y}$ : Early infant human immunodeficiency virus type 1 detection suitable for resource-limited settings with multiple circulating subtypes by use of nested threemonoplex DNA PCR and dried blood spots. J Clin Microbiol 2008, 46(2):721-726.

17. Seralem G: The effect of violence on adverse reproductive health outcomes among ANC clients in woliso town, south west shewa zone oromia regional state, Ethiopia, MPH thesis. School of Public Health Addis Ababa university; 2011.

18. De Cock KM, Fowler M, Mercier E, de Vincenzi I, Saba J, Hoff E, Alnwick DJ, Rogers M, Shaffer N: Prevention of mother-to-child HIV transmission in resource-poor countries: translating research into policy and practice. JAMA 2000, 283:1175-1182.

19. Ugochukwu EF, Kanu SO: Early infant diagnosis of HIV infection in Southeastern Nigeria: prevalence of HIV infection among HIV-exposed babies. West Afr J Med 2010, 29(1):3-7.

20. Chukwuemeka Anoje BA, Chiho S, Titilope B, Kesiena A, Michael O, Solomon O, Oluwasanmi A, Kwasi T, Chabikuli ON: Reducing mother-to-child transmission of HIV: findings from an early infant diagnosis program in south-south region of Nigeria. BMC Public Health 2012, 12:184.

21. Stringer EM, Sinkala M, Stringer JS, Mzyece E, Makuka I, Goldenberg RL, Kwape P, Chilufya M, Vermund SH: Prevention of mother-tochild transmission of HIV in Africa: successes and challenges in scaling up a nevirapine-based program in Lusaka, Zambia. AIDS 2003, 17(9):1377-1382.

22. Msellati $P$, Hingst G, Kaba F, Viho I, Welffens-Ekra C, Dabis F: Operational issues in preventing mother-to-child transmission of HIV-1 in Abidjan, Côte d'Ivoire, 1998-99. Bull World Health Organ 2001, 79:641-647.

23. Thior ILS, Smeaton LM, Shapiro RL, Wester C, Heymann SJ, Gilbert PB, Stevens $L$, Peter T, Kim S, van Widenfelt E, Moffat C, Ndase P, Arimi $P$, Kebaabetswe P, Mazonde P, Makhema J, Mclntosh K, Novitsky V, Lee TH, Marlink R, Lagakos S, Essex M, Mashi Study Team: Breastfeeding plus infant zidovudine prophylaxis for 6 months vs formula feeding plus infant zidovudine for 1 month to reduce mother-to-child HIV transmission in Botswana: a randomized trial: the Mashi Study. JAMA 2006, 296:794-805

24. WHO: Principles and recomendations for infant feeding in the context of HIV and a summary of evidence; http://www. who.int/child_adolescent_health/ documents/9789241599535/en/index.html.

25. Andrea L, Ciaranello J-EP, Ramirez-Avila L, Freedberg KA, Walensky RP, Leroy $\checkmark$ : Early infant HIV-1 diagnosis programs in resource limited settings: opportunities for improved outcomes and more cost-effective interventions. BMC Med 2011, 9:59.

26. WHO: HIV and infant feeding: Revised Principles and Recommendations Rapid Advice; http://whqlibdoc.who.int/publications/2009/9789241598873_eng.pdf.

27. Becquet R, Ekouevi DK, Menan H, Amani-Bosse C, Bequet L, Viho I, Dabis F, Timite Konan M, Leroy $\mathrm{V}$ : Early mixed feeding and breastfeeding beyond 6 months increase the risk of postnatal HIV transmission: ANRS 1201/ 1202 Ditrame Plus, Abidjan, Cote d'Ivoire. Prevent Med 2008, 47:27-33.

28. Ogundele MO, Coulter JB: HIV transmission through breastfeeding problems and prevention. Ann Trop Paediatr 2003, 23(2):91-106.

29. Coutsoudis A, Pillay K, Spooner E, Kuhn L, Coovadia HM: Influence of infant-feeding patterns on early mother -to-child transmission of HIV in Durban, South Africa: a prospective cohort study. South African Vitamin A Study Group. Lancet 1999, 354:471-476.

30. Hinda Ruton PM, Shema N, Lyambabaje A, de Dieu Bizimana J, Tsague L, Nyankesha E, Wagner CM, Mutabazi V, Nyemazi JP, Nsanzimana S, Karema C, Binagwaho A: HIV-free survival among nine- to 24-month-old children born to HIV-positive mothers in the Rwandan national PMTCT programme: a community-based household survey. J Int AIDS Soc 2012, 15:4.

31. Paranjpe SM, Phakade RS, Ingole NA, Mehta PR: Early Infant Diagnosis (EID) of HIV: an experience at a tertiary care Hospital in India. World J AIDS 2012, 2(1):1s-5s

32. Dunn DT, Newell M, Ades AE, Peckham CS: Risk of human immunodeficiency virus type 1 transmission through breastfeeding. Lancet 1992, 340:585-588.

33. Marie-Louise Newell HC, Cortina-Borja M, Rollins N, Philippe G, Francois D, for the Ghent International AIDS Society (IAS) working group on HIV infection in women and children: Mortality of infected and uninfected infants born to HIV-infected mothers in Africa: a pooled analysis. Lancet 2004, 364:1236-1243. 
34. Valeriane Leroy DKE, Renaud B, Ida V, Laurence D-M, Besigin T-G, Franc, ois R, Charlotte S, Appolinaire H, Marguerite T, Konan6 CR, Franc, ois D, for the ANRS 1201/1202 DITRAME PLUS Study Group: 18-month effectiveness of short-course antiretroviral regimens combined with alternatives to breastfeeding to prevent HIV mother-to-child transmission. PLOS ONE 2008, 3:e1645.

35. Louise Kuhn PK, Moses S, Chipepo K, Katherine S, Nancy S, Wei-Yann T, Vermund SH, Aldrovandi GM, Thea DM: Does severity of HIV disease in HIV-infected mothers affect mortality and morbidity among their uninfected infants? Clin Infect Dis 2005, 41:1654-1661.

36. Abrams EJ, Wiener J, Carter R, Kuhn L, Palumbo P, Nesheim S, Lee F, Vink P, Bulterys M, Perinatal AIDS Collaborative Transmission Study (PACTS) Group: Maternal health factors and early pediatric antiretroviral therapy influence the rate of perinatal HIV-1 disease progression in children. AIDS 2003, 17(6):867-877.

37. Blanche S, Mayaux M-J, Rouzioux C, Teglas J-P, Firtion G, Monpoux F, Cicaru-Vigneron N, Meier F, Tricoire J, Courpotin C, Vilmer E, Griscelli C, Delfraissy J-F, and the French Pediatric HIV Infection Study Group: Relation of the course of HIV infection in children to the severity of the disease in their mothers at delivery. N Engl J Med 1994, 330(5):308-312.

38. Biggar RJ, Miotti PG, Taha TE, Mtimavalye L, Broadhead R, Justesen A, Yellin F, Liomba G, Miley W, Waters D, Chiphangwi JD, Goedert JJ: Perinatal intervention trial in Africa: effect of a birth canal cleansing intervention to prevent HIV transmission. Lancet 1996, 347(9016):1647-1650.

39. Biggar RJ, Mtimavalye ML, Justesen A, Broadhead R, Miley W, Waters D, Goedert JJ, Chiphangwi JD, Taha TE, Miotti PG: Does umbilical cord blood polymerase chain reaction positivity indicate in utero (pre-labor) HIV infection? AIDS 1997, 11(11):1375-1382.

40. Biggar RJ, Janes M, Pilon R, Miotti P, Taha TE, Broadhead R, Mtimivalye L, Kumwenda N, Cassol S: Virus levels in untreated African infants infected with human immunodeficiency virus type 1.J Infect Dis 1999, 180(6):1838-1843.

doi:10.1186/1756-0500-7-309

Cite this article as: Derebe et al: Determinant and outcome of early diagnosis of HIV infection among HIV-exposed infants in southwest Ethiopia. BMC Research Notes 2014 7:309.

\section{Submit your next manuscript to BioMed Central and take full advantage of:}

- Convenient online submission

- Thorough peer review

- No space constraints or color figure charges

- Immediate publication on acceptance

- Inclusion in PubMed, CAS, Scopus and Google Scholar

- Research which is freely available for redistribution 